\title{
Produção de cenoura em função das doses de potássio em cobertura
}

\author{
Carine A Zanfirov; Carla Verônica Correa; Maristella G Carpanetti; Fernanda F Correa; Antonio Ismael \\ Inácio Cardoso \\ UNESP-FCA, Depto Prod. Vegetal, C. Postal 237, 18603-970 Botucatu-SP; ismaeldh@fca.unesp.br
}

\begin{abstract}
RESUMO
Para a produção de cenoura há a recomendação de adubação com potássio em cobertura, porém não existem trabalhos que confirmem esta necessidade. Objetivou-se avaliar o efeito de doses de potássio em cobertura na produção da cenoura híbrido Bangor. O experimento foi desenvolvido em São Manuel-SP, de 26 de maio a 30 de agosto de 2010. Foram avaliados cinco tratamentos $(0 ; 23 ; 45 ; 68$ e 90 $\mathrm{kg} \mathrm{ha}^{-1}$ de $\mathrm{K}_{2} \mathrm{O}$ em cobertura, utilizando-se o cloreto de potássio), no delineamento experimental de blocos casualizados, com cinco repetições e 40 plantas úteis por parcela. Após a colheita foram avaliadas a massa da matéria fresca da raiz e das folhas; diâmetro e comprimento da raiz. A máxima produtividade $\left(103,8 \mathrm{t} \mathrm{ha}^{-1}\right)$ foi estimada com a dose de $41,6 \mathrm{~kg} \mathrm{ha}^{-1} \mathrm{de}_{2} \mathrm{O}$. Aplicando a maior dose de $\mathrm{K}_{2} \mathrm{O}$ obteve-se menor produtividade $\left(86,1 \mathrm{t} \mathrm{ha}^{-1}\right)$ que no tratamento testemunha $\left(90,7\right.$ tha $\left.^{-1}\right)$, mostrando que a adubação em excesso, além de ser desperdício de recursos, pode prejudicar a produção.
\end{abstract}

Palavras-chave: Daucus carota, adubação, produtividade.

\begin{abstract}
Yield of carrot depending on potassium rates in top dressing

The potassium fertilization in top dressing is recommended for the carrot production. But, there are not researches that confirm this necessity. The objective of this work was to evaluate the effect of potassium rates in top dressing on the yield of carrot hybrid Bangor. The experiment was carried out in São Manuel, São Paulo state, Brazil, from May $26^{\text {th }}$ to August $30^{\text {th }}, 2010$. Five treatments $(0 ; 23$; 45 ; 68 and $90 \mathrm{~kg} \mathrm{ha}^{-1}$ of $\mathrm{K}_{2} \mathrm{O}$ in top dressing) were evaluated in randomized blocks experimental design, with five replications and 40 plants per plot. After the harvest, fresh weight of roots and shoots, diameter and length of roots were evaluated. The highest yield (103.8 $\mathrm{t} \mathrm{ha}^{-1}$ ) was estimated for $41.6 \mathrm{~kg} \mathrm{ha}^{-1}$ of $\mathrm{K}_{2} \mathrm{O}$. Lesser yield than that one obtained with the control treatment $\left(90.7 \mathrm{t} \mathrm{ha}^{-1}\right)$ was obtained with the highest rate of $\mathrm{K}_{2} \mathrm{O}\left(86.1 \mathrm{t} \mathrm{ha}^{-1}\right)$, showing that excessive fertilization, besides being more expensive, can even reduce yield.
\end{abstract}

Keywords: Daucus carota, fertilization, productivity.

(Recebido para publicação em 25 de outubro de 2011; aceito em 31 de outubro de 2012) (Received on October 25, 2011; accepted on October 31, 2012)

A cenoura (Daucus carota), pertencente à família Apiaceae, é a principal hortaliça de raiz em valor econômico e encontra-se entre as dez espécies olerícolas mais cultivadas no Brasil, com consumo per capita de 5,8 $\mathrm{kg} / \mathrm{pessoa} / \mathrm{ano}$ (Luz et al., 2009).

Segundo Murayama (1983), o sucesso da adubação depende de vários fatores, como, por exemplo, as condições climáticas e a espécie a ser plantada. Cada cultura exige quantidades de nutrientes diferentes, sendo imprescindível a análise de solo para a realização da recomendação correta da adubação.

Para o estado de São Paulo recomenda-se, no momento do plantio, a aplicação de 20; $180-360$ e $60-180$ kg ha $^{-1}$ de N, $\mathrm{P}_{2} \mathrm{O}_{5}$ e $\mathrm{K}_{2} \mathrm{O}$, respectivamente. A adubação em cobertura deve ser feita com 60-120 kg ha- de N e 30-60 kg ha ${ }^{-1}$ de $\mathrm{K}_{2} \mathrm{O}$, parcelando em 3 vezes, aos 15 , 30 e 50 dias após a germinação (Raij et al., 1997).

A disponibilidade do potássio no solo ocupa uma posição intermediária entre o nitrogênio e o fósforo, isto é, não sofre lixiviação tão intensa quanto o primeiro e nem é fixado tão fortemente quanto o segundo. O risco de lixiviação do $\mathrm{K}$ é maior nos solos arenosos, influenciando seus teores críticos no solo e na planta (Fernandes, 2006).

Sediyama et al. (1998) relataram que o potássio foi o nutriente com maior teor tanto nas folhas como nas raízes da cenoura, seguido pelo nitrogênio. Porém, segundo Filgueira (2008), poucas olerícolas respondem à aplicação de potássio em cobertura, sendo ainda pouco estudada a resposta da cenoura em relação à adubação com potássio.

Pesquisas realizadas em solos brasileiros não têm apresentado acentuada resposta à fertilização com esse nutriente, provavelmente, devido a fatores como teores de potássio adequados no solo, presença de minerais fontes de potássio, contribuição de formas não trocáveis do elemento, entre outros (Fernandes, 2006). No entanto, a adubação excessiva com potássio pode levar ao aumento na concentração salina do solo, redução na absorção de outros cátions, principalmente $\mathrm{Ca}^{++} \mathrm{e} \mathrm{Mg}^{++}$, promovendo redução da produtividade da cultura e perdas por lixiviação.

$\mathrm{Na}$ literatura brasileira, para o cultivo de cenoura, existem poucas informações referentes à aplicação de potássio em cobertura. Trabalho desta natureza foi conduzido por Luz et al. (2009) onde avaliaram a adubação com nitrogênio, potássio e cálcio aplicados em cobertura na produção comercial de cenoura e concluíram que o número total de raízes não foi afetado significativamente pelos tratamentos de adubação em cobertura. Porém, a máxima 
produtividade de raízes $\left(27,5 \mathrm{tha}^{-1}\right)$ foi obtida com a aplicação em cobertura de $229 \mathrm{~kg} \mathrm{ha}^{-1}$ do formulado de NPK 20-00-20. Neste caso, a aplicação conjunta de fontes de nitrogênio e potássio aumentou a produtividade de raízes comerciais, principalmente na classe de classificação comercial de maior valor. No entanto, como estes autores não avaliaram apenas o potássio, é difícil concluir se o aumento da produção comercial foi devido ao nitrogênio, ao potássio ou a ambos.

Em 2010 as importações de fertilizantes potássicos pelo Brasil representaram cerca de $91 \%$ do consumo interno (IBRAM, 2010), com importações da ordem de 6 milhões de toneladas. Portanto, o correto manejo da aplicação de potássio no solo é essencial para uma atividade produtiva consciente, que visa adequada produtividade e qualidade do produto, com redução de custo e respeito ao meio ambiente.

O objetivo deste trabalho foi avaliar os efeitos de doses de potássio fornecido em cobertura na produção de cenoura.

\section{MATERIAL E MÉTODOS}

$\mathrm{O}$ experimento foi conduzido no município de São Manuel-SP, de 26 de maio a 30 de agosto de 2010. O clima predominante do município de São Manuel, segundo a classificação de Köppen, é tipo $\mathrm{Cfa}$, temperado quente (mesotérmico) úmido e a temperatura média do ar do mês mais quente é superior a $22^{\circ} \mathrm{C}$, com precipitação média anual de 1377 mm (Cunha \& Martins, 2009).

O solo é um Latossolo Vermelho Distrófico Típico. É um solo arenoso, com 836,116 e $48 \mathrm{~g} \mathrm{~kg}^{-1}$ de areia, de silte e de argila, respectivamente. Os resultados obtidos na análise química, segundo metodologia de Raij et al. (2001), na camada de $0-20 \mathrm{~cm}$ de profundidade, antes da instalação do experimento foram: $\mathrm{pH}=5,6 ; \mathrm{M} . \mathrm{O}=19 \mathrm{~g} \mathrm{dm}^{-3} ; \mathrm{P}_{\mathrm{re}}$ $98 \mathrm{mg} \mathrm{dm}^{-3} ; \mathrm{H}+\mathrm{Al}=12 \mathrm{mmol}_{\mathrm{c}} \mathrm{dm}^{-3} ; \mathrm{Ca}=$ $37 \mathrm{mmol}_{\mathrm{c}} \mathrm{dm}^{-3} ; \mathrm{Mg}=13 \mathrm{mmol}_{\mathrm{c}} \mathrm{dm}^{-3}$; $\mathrm{SB}=52 \mathrm{mmol}_{\mathrm{c}} \mathrm{dm}^{-3} ; \mathrm{CTC}=64 \mathrm{mmol}_{\mathrm{c}}$ $\mathrm{dm}^{-3}$ e $\mathrm{V}=81 \%$. $\mathrm{O}$ teor de potássio $(\mathrm{K}=$ $1,9 \mathrm{mmol}_{\mathrm{c}} \mathrm{dm}^{-3}$ ) foi baixo, segundo os critérios de Raij et al. (1997). Assim, baseado nas recomendações destes au- tores, foram aplicados na adubação de plantio $120 \mathrm{~kg} \mathrm{ha}^{-1}$ de $\mathrm{K}_{2} \mathrm{O}, 20 \mathrm{~kg} \mathrm{ha}^{-1}$ de N, $180 \mathrm{~kg} \mathrm{ha}^{-1}$ de $\mathrm{P}_{2} \mathrm{O}_{5}$ e $4 \mathrm{~kg} \mathrm{~m}^{-2}$ de composto orgânico de marca comercial Provaso $^{\circledR}$. Esta adubação foi realizada seis dias antes da semeadura da cenoura (20/05/2010).

Foram fornecidos, em cobertura, 90 $\mathrm{kg} \mathrm{ha}^{-1}$ de $\mathrm{N}$ (média das doses recomendadas por Raij et al., 1997), na forma de uréia e 23, 45, 68 e $90 \mathrm{~kg} \mathrm{ha}^{-1}$ de $\mathrm{K}_{2} \mathrm{O}$, que correspondem, respectivamente, à metade da média, à média $\left(45 \mathrm{~kg} \mathrm{ha}^{-1}\right.$ de $\mathrm{K}_{2} \mathrm{O}$ ), uma vez e meia à média e duas vezes à média das doses recomendadas por Raij et al. (1997), além da testemunha sem potássio, que corresponderam aos cinco tratamentos. A adubação em cobertura foi feita de acordo com esses tratamentos, aplicando-se 1/3 de cada dose aos 15,30 e 50 dias após a germinação, utilizando-se o cloreto de potássio. O delineamento experimental foi blocos casualizados, com cinco repetições.

Foi utilizado o híbrido Bangor $\left(\right.$ Bejo $\left.^{\circledR}\right)$ e a semeadura, em canteiros de $1 \mathrm{~m}$ de largura e $20 \mathrm{~cm}$ de altura, foi em 26/05/2010 no espaçamento de 25 $\mathrm{cm}$ entre linhas e $5 \mathrm{~cm}$ entre plantas, após o desbaste. As parcelas foram de $3 \mathrm{~m}^{2}$, sendo avaliadas aproximadamente 40 plantas das duas linhas centrais da parcela. Os tratos culturais compreenderam o desbaste, capina e irrigação por aspersão, realizada, em média, três vezes por semana aplicando-se cerca de $30 \mathrm{~mm}$ de água. Não foi necessário controle de pragas e doenças.

A colheita foi realizada aos 94 dias após a semeadura, sendo avaliadas a massa da matéria fresca da parte aérea (folhas + caule) e das raízes por parcela, obtendo-se, para as raízes, a produtividade em $\mathrm{t} \mathrm{ha}^{-1}$ e para parte aérea em g por planta. Em uma amostra de dez plantas por parcela foram avaliados o comprimento e o diâmetro (dos terços superior e inferior) de cada raiz.

Os dados foram submetidos à análise de variância e análise de regressão ao nível de 5\% de significância, utilizando-se o programa Estat.

\section{RESULTADOS E DISCUSSÃO}

Não foram observadas diferenças entre os tratamentos para o compri- mento das raízes, sendo que os valores apresentaram pequena variação, de 18,0 a $18,8 \mathrm{~cm}$, sendo este tamanho ideal para comercialização. Porém, para o diâmetro das raízes, tanto superior como inferior, foram obtidos efeitos quadráticos (Figura 1). Os máximos diâmetros superior $(38 \mathrm{~mm})$ e inferior $(25 \mathrm{~mm})$ foram estimados para as doses de 47,1 e 45,0 $\mathrm{kg} \mathrm{ha}^{-1}$ de $\mathrm{K}_{2} \mathrm{O}$, respectivamente. No entanto, apesar de significativos, as diferenças entre o maior e o menor diâmetro superior foi de apenas $3 \mathrm{~mm}$, assim como o inferior, valores quase imperceptíveis e, portanto, de pequena importância comercial. Os valores de diâmetro foram semelhantes aos obtidos por Ferreira et al. (2011) com a cultivar Brasília colhida aos 95 dias após a semeadura.

As doses de potássio em cobertura tiveram efeito quadrático sobre a produtividade de raízes de cenoura (Figura 2). A máxima produtividade, 103,8 $\mathrm{t} \mathrm{ha}^{-1}$, foi estimada para a dose de $41,6 \mathrm{~kg} \mathrm{ha}^{-1}$ de $\mathrm{K}_{2} \mathrm{O}$, decrescendo após este valor. Resultados semelhantes foram obtidos para a massa da matéria fresca da parte aérea, com máximo de $90,4 \mathrm{~g}$ por planta para a dose de $42,7 \mathrm{t} \mathrm{ha}^{-1}$ (Figura 3).

Luz et al. (2009) concluíram que a produtividade máxima de cenoura $(27,5$ $\mathrm{t} \mathrm{ha}^{-1}$ ) foi obtida com a aplicação de 229 $\mathrm{kg} \mathrm{ha}^{-1}$ do formulado 20-00-20, ou seja $\mathrm{N}+\mathrm{K}_{2} \mathrm{O}$, em cobertura. Porém, estes autores não isolaram os efeitos do $\mathrm{N}$ e do K. Na presente pesquisa, fixou-se a dose de $\mathrm{N}$ em cobertura $\left(90 \mathrm{~kg} \mathrm{ha}^{-1}\right)$ e variou-se apenas o K. No entanto, a máxima produtividade foi obtida com doses semelhantes de $\mathrm{K}_{2} \mathrm{O}$, pois $229 \mathrm{~kg}$ deste formulado correspondem a $45,8 \mathrm{~kg}$ de $\mathrm{K}_{2} \mathrm{O}$. Estes resultados coincidem com a recomendação de Raij et al. (1997) para o estado de São Paulo (30 a 60 kg $\mathrm{ha}^{-1}$ de $\mathrm{K}_{2} \mathrm{O}$ ).

Segundo Filgueira (2008), poucas olerícolas respondem à aplicação de potássio em cobertura e não existem pesquisas para comprovar a necessidade desta aplicação. Porém, o potássio é o nutriente com maior teor tanto nas folhas como nas raízes da cenoura (Sediyama et al., 1998). O potássio tem como uma de suas funções na planta o transporte de carboidratos da fonte (folhas) para os drenos (Taiz \& Zeiger, 2004), que, no 


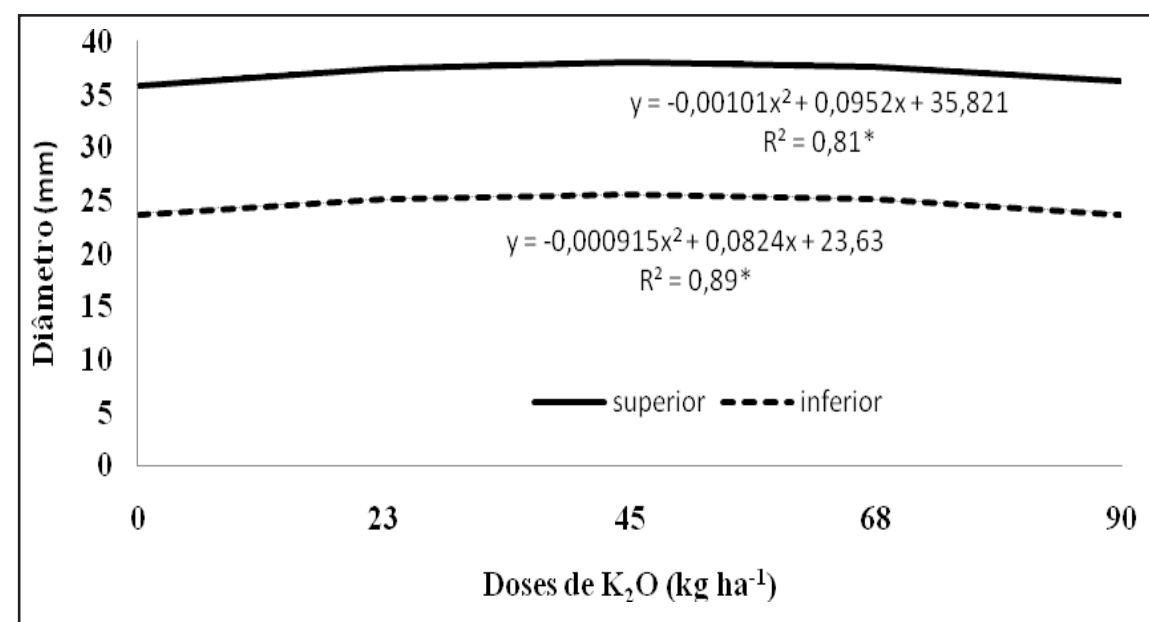

Figura 1. Diâmetros superior e inferior das raízes de cenoura em função das doses de potássio $\left(\mathrm{K}_{2} \mathrm{O}\right)$ em cobertura (superior and inferior diameter of carrot roots depending on potassium $\left(\mathrm{K}_{2} \mathrm{O}\right)$ rates in top dressing). Botucatu, UNESP, 2010.

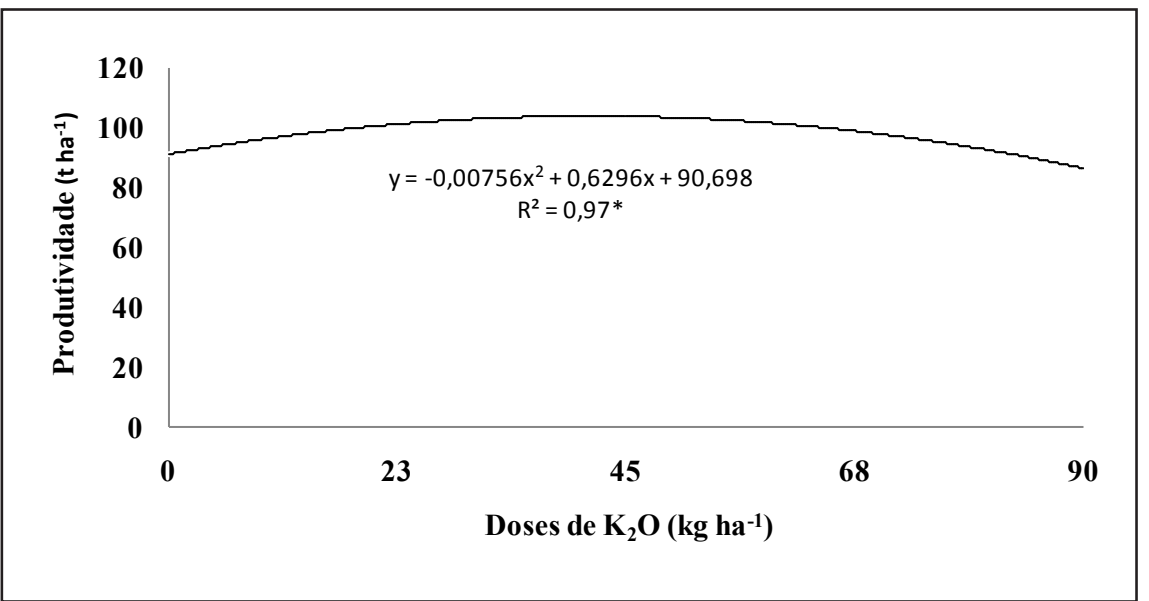

Figura 2. Produtividade de raízes de cenoura em função das doses de potássio $\left(\mathrm{K}_{2} \mathrm{O}\right)$ em cobertura (yield of carrots depending on potassium $\left(\mathrm{K}_{2} \mathrm{O}\right)$ rates in top dressing). Botucatu, UNESP, 2010.

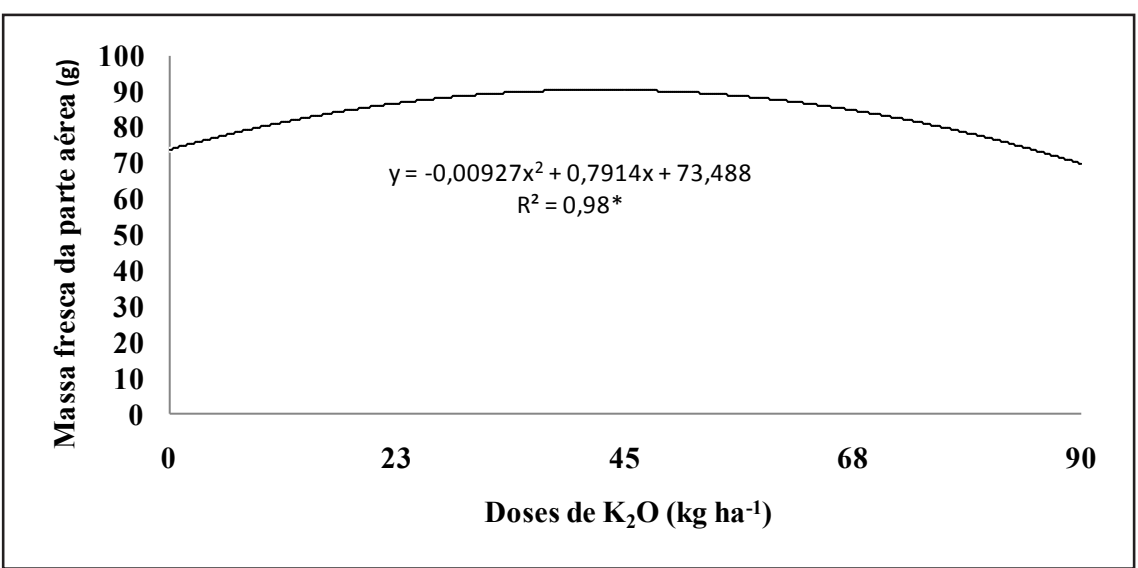

Figura 3. Massa da matéria fresca da parte aérea de plantas de cenoura em função das doses de potássio $\left(\mathrm{K}_{2} \mathrm{O}\right)$ em cobertura (shoot fresh weight of carrot plants depending on potassium $\left(\mathrm{K}_{2} \mathrm{O}\right)$ rates in top dressing). Botucatu, UNESP, 2010. caso da cenoura, são as raízes tuberosas.

$\mathrm{Na}$ comparação entre a máxima produtividade $\left(103,8 \mathrm{t} \mathrm{ha}^{-1}\right)$ obtida com $41,6 \mathrm{~kg} \mathrm{ha}^{-1}$ de $\mathrm{K}_{2} \mathrm{O}$ e a testemunha sem aplicação de potássio $\left(90,7 \mathrm{t} \mathrm{ha}^{-1}\right)$ a diferença foi de apenas 14\%, valor pequeno se comparado ao relatado por Luz et al. (2009), 27\%, na comparação entre a melhor dose de nitrogênio e potássio em cobertura e a testemunha. Porém, apesar de a diferença ter sido pequena (14\%), houve aumento na produtividade, mesmo com a aplicação de formulado NPK e matéria orgânica no plantio e nitrogênio em cobertura em todos os tratamentos, confirmando a necessidade da suplementação com potássio em cobertura. Ressalta-se que a irrigação foi por aspersão, o que pode favorecer a perda de potássio por lixiviação, ainda mais em um solo arenoso como o desta pesquisa, com $836 \mathrm{~g} \mathrm{~kg}^{-1}$ de areia. As irrigações foram realizadas três vezes por semana, com uma lâmina média de $30 \mathrm{~mm}$ em cada irrigação.

Foram obtidas elevadas produtividades de raízes, com média de 96,0 t ha-1, e máxima de $103,8 \mathrm{t} \mathrm{ha}^{-1}$; estes valores são superiores ao máximo obtido por Oliveira et al. (2001) (79,5 t ha-1), com a combinação de húmus e adubo mineral, por Mesquita Filho et al. (2002) (37,0 $\mathrm{t} \mathrm{ha}^{-1}$ ), com a combinação de adubação fosfatada e composto de lixo, por Luz et al. (2009) (27,5 t ha-1), avaliando doses de NK e por Trani et al. (2006) (49,4 t $\mathrm{ha}^{-1}$ ), quando avaliaram a produtividade de cenoura e alface em cultivo sucessivo e o efeito do calcário por três anos. Provavelmente as elevadas produtividades obtidas na presente pesquisa devam-se à obtenção de uma população de plantas sem falhas, clima favorável à cultura, que prefere clima ameno, utilização de híbrido bem adaptado e ausência de patógenos e pragas. A maioria das pesquisas citadas foram realizadas com cultivares de polinização aberta, geralmente 'Brasília', e nem sempre nas condições ideais. Além disto, híbridos geralmente apresentam maior uniformidade e heterose, favorecendo a obtenção de maiores produtividades (Maluf, 2001). A uniformidade no comprimento e diâmetro das raízes foi muito grande e os valores estavam muito 
próximos da faixa ideal, favorecendo o aproveitamento de praticamente 100\% das raízes. Ferreira et al. (2011), avaliando épocas de colheita de raízes da cultivar Brasília, obtiveram comprimento inferior a $16 \mathrm{~cm}$, o que compromete a produtividade. Porém, poucos autores avaliam o comprimento e diâmetro das raízes, características essenciais para a determinação da produtividade. Nesta pesquisa, as doses estimadas para a máxima produtividade $\left(41,6 \mathrm{~kg} \mathrm{ha}^{-1}\right)$ foram próximas às dos máximos diâmetros (45,0 e 47,1 $\mathrm{kg} \mathrm{ha}^{-1}$, para os diâmetros superior e inferior, respectivamente).

Ao contrário desta pesquisa, Salata et al. (2011), avaliando a produtividade de ervilha torta em função de doses de potássio em cobertura, não observaram incrementos de número e massa de vagens por planta em função das doses aplicadas. Também Godoy et al. (2012), estudando doses de potássio em cobertura em couve-flor, não observaram resultados significativos para o diâmetro médio da cabeça e o número de folhas por planta, e concluíram que a aplicação de potássio apenas no plantio seria suficiente. Araújo (2011), estudando doses de potássio em cobertura, não observou diferença na produtividade de frutos em abobrinha-de-moita, tanto no cultivo de outono como de primavera. Todos estes autores realizaram suas pesquisas neste mesmo solo e durante o período de poucas chuvas, com exceção de uma das épocas (primavera) na pesquisa de Araújo (2011).

Muitas vezes há um exagero por parte dos produtores na aplicação de adubos, tanto no plantio como em cobertura. Observou-se que na maior dose avaliada a produtividade $\left(86,1 \mathrm{t} \mathrm{ha}^{-1}\right)$ foi menor que na testemunha sem aplicação de potássio em cobertura $\left(90,7\right.$ t ha $\left.^{-1}\right)($ Figura
2). O mesmo ocorreu com a massa da matéria fresca da parte aérea, com 73,5 e 69,6 $\mathrm{g} \mathrm{planta}^{-1}$ na testemunha e na maior dose $\left(90 \mathrm{~kg} \mathrm{ha}^{-1}\right)$, respectivamente (Figura 3). Adubação em excesso, além de ser desperdício de recursos, pode prejudicar a produção, como observado nesta pesquisa, e ainda pode favorecer a contaminação do lençol freático. Portanto, uma adubação equilibrada é fundamental para a obtenção de elevada produtividade e qualidade de raízes, sem desperdícios.

\section{AGRADECIMENTOS}

Os autores agradecem à FAPESP e ao CNPq, pela concessão de bolsas.

\section{REFERÊNCIAS}

ARAÚJO HS. 2011. Doses de potássio em cobertura na produção e qualidade de frutos de abobrinha-de-moita. Botucatu: UNESPFCA. 92p (Dissertação mestrado).

CUNHA AR; MARTINS D. 2009. Classificação climática para os municípios de Botucatu e São Manuel, SP. Irriga 14: 1-11.

FERNANDES MS. 2006. Nutrição mineral de plantas. Viçosa: Sociedade Brasileira de Ciências do Solo. 432p.

FERREIRA RMA; AROUCHA EMM; MESQUITA HC; FREITAS FCL; NUNES GH S. 2011. Qualidade pós-colheita de cenoura durante o desenvolvimento em monocultivo e consorciada com rabanete. Revista Ciência Agronômica 42: 423-428.

FILGUEIRA FAR. 2008. Novo manual de olericultura: agrotecnologia moderna na produção e comercialização de hortaliças. Viçosa: UFV. 421p.

GODOY AR; SALATA AC; KANO C; HIGUTI ARO; CARDOSO AII; EVANGELISTA RM. 2012. Produção e qualidade de couve-flor com diferentes doses de potássio em cobertura. Scientia Agrária Paranaensis 11:.

IBRAM (Instituto Brasileiro de Mineração). 2010. Informações e análises da economia mineral brasileira (Fosfato/Potássio/Fertilizantes).
Disponível em: http://www.ibram.org.br/ sites/1300/1382/00001150.pdf. Acesso em 15/03/2011.

LUZ JMQ; FILHO AZ; RODRIGUES WL; RODRIGUES CR; QUEIROZ AA. 2009. Adubação de cobertura com nitrogênio, potássio e cálcio na produção comercial de cenoura. Horticultura Brasileira 27: 543-548.

MALUF WR. 2001. Heterose e emprego de híbridos $\mathrm{F}_{1}$ em hortaliças. In: NASS LL; VALOIS ACC; MELO IS; VALADARES MC. (eds). Recursos genéticos e melhoramento: plantas. Rondonópolis: Fundação MT. p. 327-356.

MESQUITA FILHO MV; SOUZA AF; MOITA AW; RAMAGEM RD. 2002. Produção comercializável e teores de $\mathrm{Cu}$ e $\mathrm{Zn}$ em cenoura em decorrência da ação residual de fósforo e composto de lixo em solo sob cerrado. Horticultura Brasileira 20: 153-157.

MURAYAMA S. 1983. Horticultura. 2ed. Campinas: Instituto Campineiro de Ensino Agrícola. 432p.

OLIVEIRA AP; ESPINOLA FEJ; ARAÚJO JS; COSTA CC. 2001. Produção de raízes de cenoura cultivadas com húmus de minhoca e adubo mineral. Horticultura Brasileira 19: 77-80.

RAIJ B; CANTARELLA H; QUAGGIO JA; FURLANI AMC. 1997. Recomendações de adubação e calagem para o estado de São Paulo. 2. ed. Campinas: Instituto Agronômico e Fundação IAC. 285p.

RAIJ B; ANDRADE JC; CANTARELLA H; QUAGGIO JA. 2001. Análise química para avaliação da fertilidade de solos tropicais. Campinas: Instituto Agronômico de Campinas. 285p.

SALATA AC; KANO C; GODOY AR; EVANGELISTA RM; CARDOSO AII. 2011. Produção e qualidade de frutos de ervilha torta submetidas a diferentes níveis de adubação potássica. Nucleus 8: 127-134.

SEDIYAMA MAN; VIDIGAL SM; PEREIRA PRG; GARCIA NCP; DELIMA PC. 1998. Produção e composição mineral de cenoura adubada com resíduos orgânicos. Bragantia 57: 379-386.

TAIZ L; ZEIGER E. 2004. Fisiologia vegetal. Porto Alegre: Artmed. 719p.

TRANI PE; MINAMI K; RAIJ B; SAKAI E; MELLO SC; TIVELLI SW. 2006. Calagem em cultivos sucessivos de cenoura e alface. Horticultura Brasileira 24: 59-64. 